\title{
Experimental Measurements of a Low Power CMOS Analog MPPT Power Conditioning Circuit for Energy Harvesting Applications
}

\author{
Francarl Galea ${ }^{1}$, Owen Casha, Ivan Grech, Edward Gatt and Joseph Micallef \\ Department of Microelectronics and Nanoelectronics \\ University of Malta \\ ${ }^{1}$ Email: francarl.galea@um.edu.mt
}

\begin{abstract}
This paper presents the complete measured performance and characterization of a fabricated power conditioning integrated circuit for energy harvesters with on-chip maximum power point tracking (MPPT) and external energy storage. This ultra-low power circuit employs an AC/DC-to-DC converter compatible with both $\mathrm{AC}$ and $\mathrm{DC}$ voltage energy harvesters. The MPPT design follows the perturbation and observation algorithm. This MPPT is capable of tracking the maximum power point of types of energy harvesters. The circuit is implemented using the AMS CMOS $0.35 \mu \mathrm{m}$ high voltage technology and all the circuit blocks use analog electronic techniques, with the transistors operating in the sub-threshold region, in order to obtain a minimum power consumption. This power conditioning circuit consumes less than $2 \mu \mathrm{W}$ while featuring an input voltage range of $\pm 0.5 \mathrm{~V}$ to $\pm 50 \mathrm{~V}$ and a power range from $10 \mu \mathrm{W}$ to $200 \mathrm{~mW}$.

Index Terms-Power conditioning circuits, Perturb and observe MPPT algorithm, Energy harvesters, MPPT, Sub-threshold analog operation, Integrated AC-DC Dual Boost converter, Low power low frequency on-chip oscillators.
\end{abstract}

\section{INTRODUCTION}

Energy harvesting devices are capable of gathering energy from their surrounding environment and converting it into electrical energy. Small energy harvesters are capable of powering small electrical loads. These devices eliminate the need of a battery, in applications where battery replacement might not be feasible [1]. Such applications may include sensors monitoring structural health, natural disasters and air quality [2]. In medicine, energy harvesting technology can be applied in pacemakers and cochlear implants [3]. Wildlife and maritime organisations can use trackers or sensors powered by energy harvesters in order to increase the lifetime of such devices used to monitor the habitat of certain species. A common disadvantage of energy harvesters is that their output is highly volatile because it depends on their current operating conditions. Thus, it is beneficial to have a power conditioning circuit to provide energy storage in order to minimize the downtime of the loads and a voltage regulation circuit to generate a constant output voltage. Energy harvesters also have an equivalent internal impedance, therefore requiring maximum power point tracking (MPPT) to match the load resistance to the internal impedance of the energy harvester. Through the use of a switch-mode converter, maximum power from the harvester can be obtained. A block diagram of the power conditioning circuit proposed in [4] is shown in Fig. 1. The first stage of the power conditioner consists of an AC/DCto-DC converter controlled by an MPPT controller. Prototypes of this integrated circuit were fabricated and its measured results and characterization are being presented in this paper. This architecture makes use of a direct AC-DC converter using the Improved Dual Boost converter [5]. It was also further improved for better efficiency and performance. Due to this type of converter, no rectification is required when connecting the proposed power conditioning circuit with energy harvesters having an AC output voltage. Consequently another novelty of the proposed power conditioning circuit is that the adopted MPPT algorithm can work with piezoelectric, pyroelectric, photovoltaic, electromagnetic, electrostatic and thermoelectric energy harvesters and operate all types and models of energy harvester at maximum power point since they all obey the same current-voltage transfer characteristic curve. The MPPT controller is capable of reaching MPP by only sensing the output voltage as in [6], [7] and therefore there is no need of current sensing which is a high power dissipating circuit block. All the control circuitry is implemented in analogue electronics in order to obtain a high efficiency because microprocessors, ADCs, DACs and clock generators demand a substantial amount of power which is sometimes higher than the power available from such energy harvesters. Additionally all the transistors operate in the sub-threshold region in order to limit the power dissipation in the transistors, thus further increasing the energy efficiency.

\section{AC/DC TO DC CONVERTER WITH MPPT FUNCTION}

The power conditioning circuit uses an AC/DC-to-DC converter as shown in Fig. 2 so that, while eliminating the losses incurred by a rectification block, it is still capable to work with both AC and DC energy harvesters. Modifications were carried out on the converter proposed in [5] in order to obtain better efficiency levels as explained in [4]. The circuit is designed to work with a wide input voltage range $( \pm 0.5 \mathrm{~V}$ to $\pm 50 \mathrm{~V}$ ) and a power range from $10 \mu \mathrm{W}$ to $200 \mathrm{~mW}$. This circuit requires an externally connected inductor of $1 \mathrm{mH}$ and a $100 \mathrm{nF}$ storage capacitor. The control circuitry of both blocks requires a $1 \mathrm{~V}$ supply voltage which will be supplied by one of the regulators in the voltage regulating DC-DC converters 
block, which is currently being fabricated. The AC/DC-to-DC converter is designed to work as a normal full wave rectifier when its control circuitry is off due to lack of supply voltage to its control. A minimum voltage of $1.5 \mathrm{~V}$ is required at the input of the AC/DC - DC converter to cold start the voltage regulating DC-DC converter and generates the $1 \mathrm{~V}$ supply voltage required for all the control circuitry.

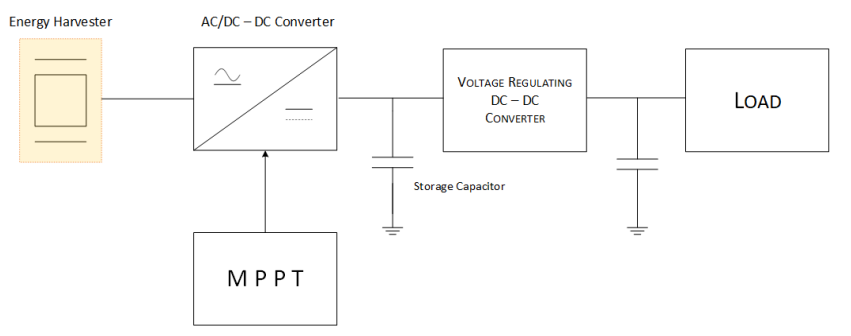

Fig. 1. Block diagram of the proposed power conditioning circuit [4].

The circuit implementation of the perturbation and observation $(\mathrm{P \& O}) \mathrm{MPPT}$ algorithm control for the AC/DC-to-DC converter is shown in Fig. 3 [4]. The circuit is implemented using the AMS CMOS $0.35 \mu \mathrm{m}$ high voltage technology and all the circuit blocks were designed in analog electronics, operating in the sub-threshold region in order to guarantee minimum power consumption. The control circuitry including the MPPT function consumes a total power of $2 \mu \mathrm{W}$.

The MPPT algorithm is implemented around a sample and hold $(\mathrm{S} \& \mathrm{H})$ circuit and a clocked comparator, and it operates at a clock frequency of $15 \mathrm{~Hz}$. This MPPT control loop only requires a voltage feedback which eliminates the need of current sensing and a multiplier block, thus further reducing the power consumption [6], [7]. During simulation, it was confirmed that if the input power and the load current are either constant or change at a slow rate, maximum power transfer is maintained [4]. The MPPT control circuit gets feedback from the output of the converter, meaning that the converter efficiency is part of the control loop. The S\&H circuit stores the previous output voltage and after one clock cycle, the clocked comparator compares the current output voltage with the previous output voltage stored in the $\mathrm{S} \& \mathrm{H}$. If the comparator detects that the output voltage is decreasing, it changes the state of the toggle

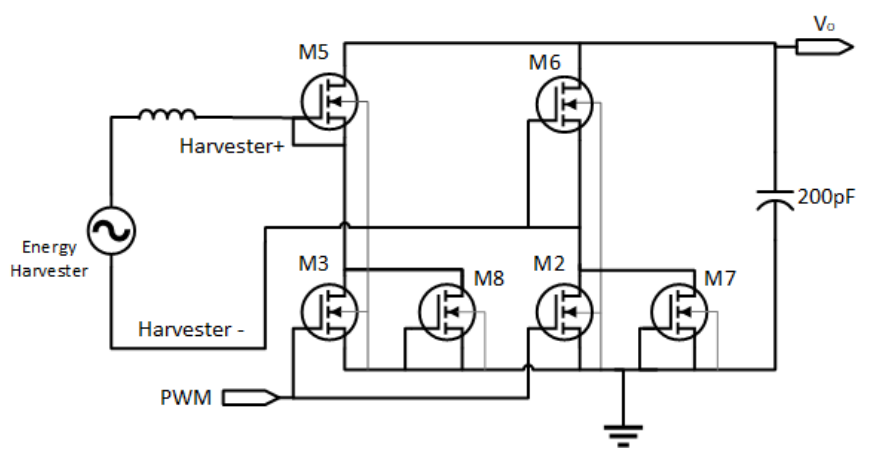

Fig. 2. Improved Dual Boost AC/DC to DC converter [4], [5].

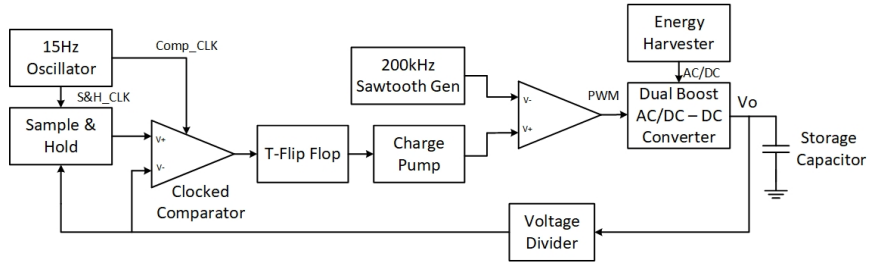

Fig. 3. Circuit implementation of the perturbation and observation MPPT algorithm control for the AC/DC-to-DC converter [4].

flip flop. Depending on the output state of this flip flop, the charge pump either continuously increases or decreases its output voltage. The output voltage of the charge pump is the reference voltage for the pulse width modulation (PWM) generator and controls the duty cycle at which the converter is operated. A $200 \mathrm{kHz}$ sawtooth generator needed for PWM generation is also integrated in the circuit. The transistors of the converter are switched at this frequency. By varying the duty cycle of the converter, the resistance of the output load is varied until the load resistance matches the internal resistance of the energy harvester. Since the output voltage of the converter is capable to reach a voltage of $50 \mathrm{~V}$, whereas the control voltages work in the range of $0 \mathrm{~V}$ to $1 \mathrm{~V}$, a voltage divider had to be implemented on-chip so that the output voltage is scaled down by a factor of 50 before it is fed back to the control circuit [4].

\section{LAYOUT CONSIDERATIONS OF THE AC/DC-TO-DC CONVERTER WITH MPPT CONTROL}

Following the circuit design and simulations at various temperature, voltage and process conditions [4], [8], the physical layout of the circuit was designed. The circuit layout is shown in Figure 4, with all the respective blocks labelled. The layout includes four high voltage pads and sixteen low voltage pads as shown in Figure 5. Pads were included at the input and output of every block, so that each individual block could be monitored externally and maximize its testability. The dimension of the integrated circuit, including the pads, is $1271 \mu \mathrm{m}$ by $1347 \mu \mathrm{m}$, that is an area of $1.7 \mathrm{~mm}^{2}$. The active circuit's dimensions are $400 \mu \mathrm{m}$ by $300 \mu \mathrm{m}$ and covers an area of $0.11 \mathrm{~mm}^{2}$.

Post-layout simulations were carried out in order to assess the effect of the pads on the total power consumption and the functionality of the circuit blocks. This was particularly relevant for the output pads of the sawtooth generator and the gate driver which switch at a frequency of $200 \mathrm{kHz}$. The additional load capacitance substantially increased the power consumption. Post-layout simulations including only the essential pads resulted in a power consumption of $1.2 \mu \mathrm{W}$. When all the redundant testing pads were included to the postlayout simulation, slight modifications to the circuitry had to be carried out, particularly to the current biasing in order for the oscillators to maintain the desired oscillating frequency. The post-layout simulated power consumption with the testing pads included, increased to $8.1 \mu \mathrm{W}$. The power consumption 


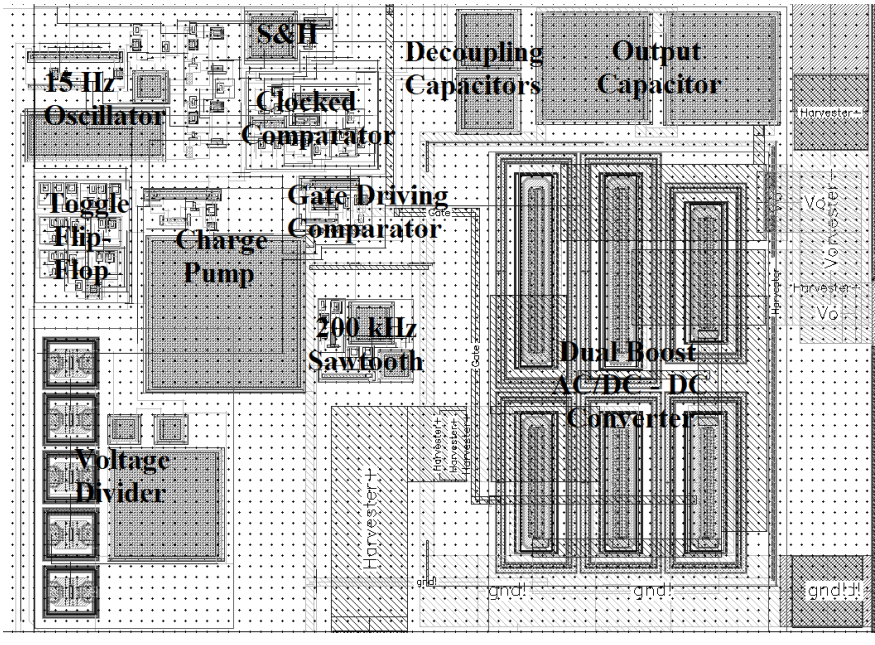

Fig. 4. Layout of the AC/DC-to-DC converter with MPPT control.

of the fabricated integrated circuit was measured to be $10 \mu \mathrm{W}$ which is slightly higher than the consumption obtained in postlayout simulations when including all the redundant testing pads. However, if this circuit is fabricated without these testing pads, the static power consumption is expected to drop back to below $2 \mu \mathrm{W}$.

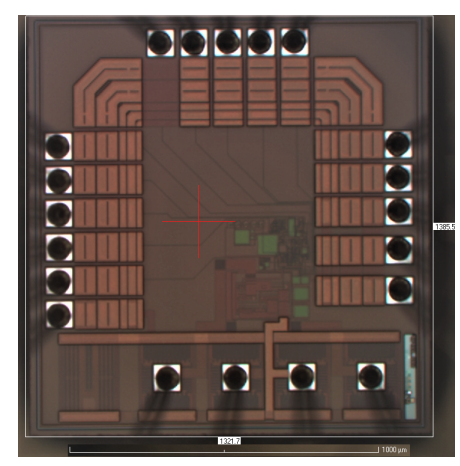

Fig. 5. Micro-photograph of the fabricated integrated circuit.

The measured results obtained during the testing of individual circuit blocks such as the integrated ultra low frequency, low power oscillators, the PWM generator, voltage divider and the efficiency levels obtained by the integrated improved AC/DC-to-DC dual boost converter were published in [9], whereas this paper presents the measured results of the complete circuit, particularly its performance at various input voltage, input series resistance and output load conditions.

\section{EXPERIMENTAL MEASUREMENTS OF THE MPPT}

A number of minor changes had to be carried out in order for the MPPT to work reliably during the practical testing. The MPPT clock frequency was slowed from $15 \mathrm{~Hz}$ to $10 \mathrm{~Hz}$ because in some cases, the changing duty cycle required a longer time period for the boost converter to respond. This change required a slower charge pump. Originally, the charge pump had an on-chip capacitance of $1 \mathrm{pF}$ which is charged or

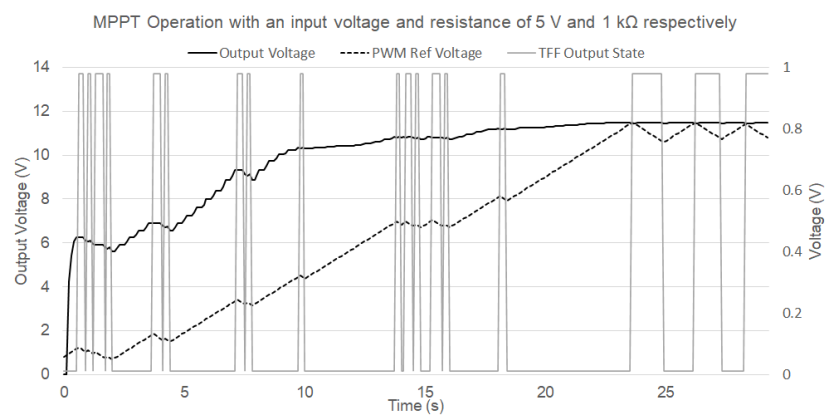

Fig. 6. MPPT operation of the fabricated prototype at an input voltage of $5 \mathrm{~V}$, an input resistance of $1 \mathrm{k} \Omega$ and output load of $90 \mathrm{k} \Omega$.

discharged at a constant current of $1 \mathrm{nA}$. The charge pump output transient response was slowed down by adding an additional capacitor, which was connected externally.

In order to be able to analyse the MPPT's operation in detail without any external changes, the circuit was initially connected to a voltage supply and external input resistance or capacitance to model various types of energy harvesters was used. The MPPT circuit was tested at various operating conditions including $\mathrm{AC}$ and $\mathrm{DC}$ input voltages. This was done by varying the input voltage, the input series resistance and the output load resistance. The output voltage, the charge pump voltage and the toggle flip flop state were continuously monitored at a sampling period of $1 \mathrm{~ms}$. Fig. 6 shows how the MPPT circuit behaves when matching an output load of $90 \mathrm{k} \Omega$ to an input series resistance of $1 \mathrm{k} \Omega$, operated with an input voltage of $5 \mathrm{~V}$. The PWM reference voltage is generated by the charge pump which is controlled by the TFF output state. The MPPT settling time is $22 \mathrm{~s}$ and the output voltage settles at $11.5 \mathrm{~V}$. When the maximum output voltage is reached by the MPPT, the voltage across the internal resistance should be equal to the voltage across the converter. During this test, at maximum power point, the voltage across the series resistance is $1.5 \mathrm{~V}$, meaning that the converter's input voltage is $3.5 \mathrm{~V}$. This means that the MPPT is capable of generating a higher output power by maintaining a higher voltage across the converter and the reason being that at a lower voltage, the converter's efficiency drops. The input power of the converter is $5.25 \mathrm{~mW}$ whereas its output power is $1.5 \mathrm{~mW}$. The boost converter manages to boost the voltage by a factor of 3.25 at an efficiency of $24 \%$. On the other hand the MPPT's efficiency is $99.96 \%$ when steady state is reached.

Fig. 7 shows how the MPPT circuit behaves when matching an output load of $90 \mathrm{k} \Omega$ to an input series resistance of $4.7 \mathrm{k} \Omega$ and operating it with an input voltage of $2 \mathrm{~V}$. The MPPT settling time is $8 \mathrm{~s}$ and the output voltage settles at $3.3 \mathrm{~V}$. During this test, at maximum power point, the voltage across the series resistance is $0.9 \mathrm{~V}$ which means that the converter's input voltage was $1.1 \mathrm{~V}$. This shows that the MPPT obtained more power output by maintaining a slightly higher voltage across the converter. The input power of the converter is $191 \mu \mathrm{W}$ whereas its output power is $121 \mu \mathrm{W}$. The efficiency 


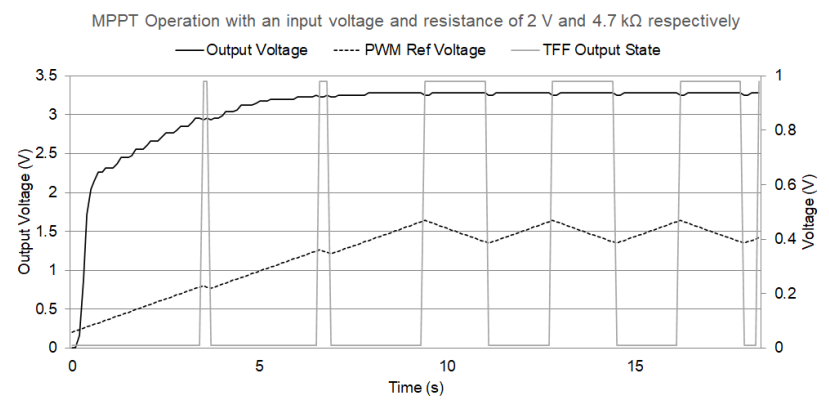

Fig. 7. MPPT operation of the fabricated prototype at an input voltage of $2 \mathrm{~V}$, an input resistance of $4.7 \mathrm{k} \Omega$ and an output load of $90 \mathrm{k} \Omega$.

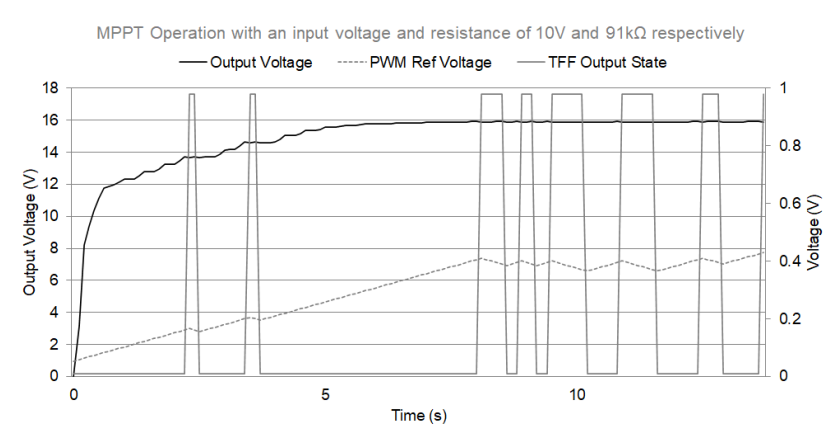

Fig. 8. MPPT operation of the fabricated prototype at an input voltage of $10 \mathrm{~V}$, an input resistance of $2.2 \mathrm{k} \Omega$ and an output load of $90 \mathrm{k} \Omega$.

of the converter is $63.4 \%$. The MPPT's efficiency is $99.90 \%$.

Fig. 8 shows how the MPPT circuit behaves when matching an output load of $90 \mathrm{k} \Omega$ to an input series resistance of $2.2 \mathrm{k} \Omega$ while being operated with an input voltage of $10 \mathrm{~V}$. The MPPT settling time is $7.9 \mathrm{~s}$ and the output voltage settles at $15.93 \mathrm{~V}$. During this test, at maximum power point, the voltage across the series resistance is $2.7 \mathrm{~V}$ which means that the converter's input voltage is $7.3 \mathrm{~V}$. This shows that the MPPT obtained more power output by maintaining a higher voltage across the converter. The input power of the converter is $8.96 \mathrm{~mW}$ whereas its output power is $2.82 \mathrm{~mW}$. The efficiency of the converter is $31.5 \%$. The MPPT's efficiency is $99.86 \%$, which is slightly lower than the previous measurements, due to a drop in the output voltage to $15.87 \mathrm{~V}$ between the toggled states of the flip flop.

The integrated circuit was tested over a wide range of input voltages, input resistance and output load. Plots of these tests including the boost conversion efficiency, the MPPT efficiency, the input power and the output power against the input voltage are shown in Fig. 9. The MPPT efficiency exceeded 99\% in all tests. Conversion efficiency reached a maximum of $63 \%$ mainly because of the inefficiencies incurred by the integrated AC/DC-to-DC dual boost converter. Fig. 10 shows the measured input $\mathrm{AC}$ voltages before and after the input resistance of $1 \mathrm{k} \Omega$ when the circuit is being tested with a peak input voltage of $1.75 \mathrm{~V}$ at a frequency of $1 \mathrm{kHz}$. The output DC voltage reached $4 \mathrm{~V}$ across an output load of $64 \mathrm{k} \Omega$.

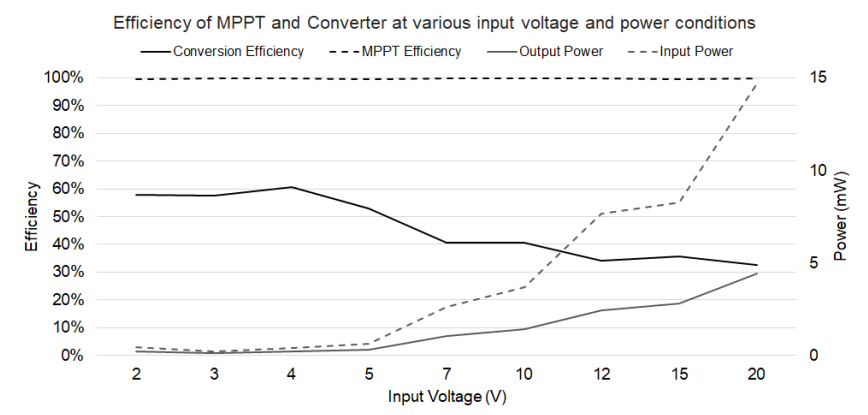

Fig. 9. Measured efficiency of the MPPT and the AC/DC-to-DC converter of the fabricated prototype at various input voltage and power conditions.

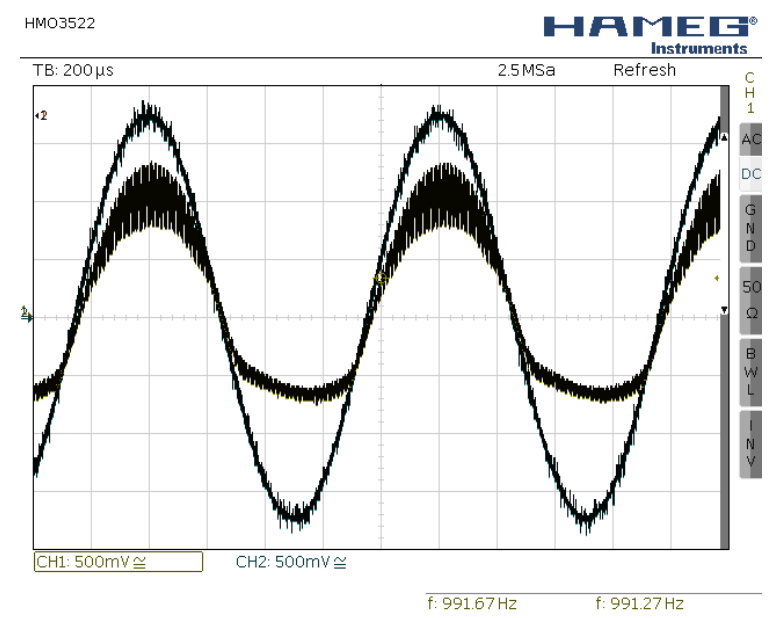

Fig. 10. Input voltage measured before and after the input resistance during the MPPT operation at a peak AC input voltage of $1.75 \mathrm{~V}, 1 \mathrm{kHz}$.

\section{CONClusions AND Further Work}

This paper presented the measured results of the complete testing of the AC/DC-to-DC converter with MPPT algorithm. These results show that the novel circuitry implemented in this power conditioning circuit works as predicated by the simulations [4], [8]. If this circuit is fabricated without the redundant testing pads, the static power consumption is expected to be less than $2 \mu \mathrm{W}$. The integrated AC/DC-to-DC converter works as expected with a peak efficiency of 63\% [9]. Additional improvements in the converter which further increase the conversion efficiency are possible. One improvement is to increase the sizes of the high voltage transistors in the switch mode converter. Paralleling of pads and track widening of connections carrying the input and output currents of the converter are other possible improvements which increase the conversion efficiency but consume more silicon area. For monitoring and testability purposes, an output pad was connected to the gates of the high power transistors in the converter. The added pad stray capacitance to the gate capacitance of the power transistors increased the switching times of the converter, thus increasing further the switching losses. This pad is completely redundant and can be eliminated from the circuit. Its removal increases the converter's conversion 
TABLE I

COMPARISON OF THE ON-CHIP AC/DC-DC CONVERTER WITH THE SOA.

\begin{tabular}{|c|l|l|l|l|l|c|}
\hline & $V_{I N}$ & $V_{O}$ & $\eta$ & $P_{I N}$ & $P_{O}$ & Technology \\
\hline \hline$[10]$ & $80 \mathrm{Vp}-\mathrm{p}$ & N/A & $61 \%$ & $\begin{array}{l}10 \mu \mathrm{W} \\
-1 \mathrm{~mW}\end{array}$ & N/A & $\begin{array}{c}0.35 \mu \mathrm{m}+ \\
\text { Discrete }\end{array}$ \\
\hline$[11]$ & $0.35-1.2 \mathrm{~V}$ & $2.7-4.5 \mathrm{~V}$ & $41 \%$ & $30 \mu \mathrm{W}$ & $7.1 \mu \mathrm{W}$ & Discrete \\
\hline$[12]$ & N/A & $2.4 \mathrm{~V}$ & $60 \%$ & $277 \mu \mathrm{W}$ & $165 \mu \mathrm{W}$ & $0.25 \mu \mathrm{m}$ \\
\hline$[13]$ & $0.125-0.4 \mathrm{~V}$ & $0-2.5 \mathrm{~V}$ & $13 \%$ & N/A & $40 \mu \mathrm{W}$ & $90 \mathrm{~nm}$ \\
\hline$[14]$ & $0.5-2.5 \mathrm{~V}$ & $3 \mathrm{~V}$ & $60 \%$ & N/A & $3.9 \mathrm{~mW}$ & $0.5 \mu \mathrm{m}$ \\
\hline $\begin{array}{l}\text { This } \\
\text { Work }\end{array}$ & $\pm 0.5- \pm 50 \mathrm{~V}$ & $1-50 \mathrm{~V}$ & $63 \%$ & $\begin{array}{l}10 \mu \mathrm{W}- \\
200 \mathrm{~mW}\end{array}$ & $\begin{array}{l}1 \mu \mathrm{W} \\
-60 \mathrm{~mW}\end{array}$ & $0.35 \mu \mathrm{m}$ \\
\hline
\end{tabular}

TABLE II

COMPARISON OF THE ON-CHIP MPPT WITH THE SOA.

\begin{tabular}{|l|l|l|l|l|l|c|}
\hline & $V_{I N}$ & $V_{O}$ & MPPT $\eta$ & $P_{I N}$ & $P_{O}$ & Technology \\
\hline \hline$[6]$ & $\begin{array}{l}0.21-0.65 \\
\text { VDC }\end{array}$ & $0.6-1.8 \mathrm{~V}$ & $\begin{array}{l}95.7- \\
99.8 \%\end{array}$ & N/A & $1 \mathrm{~mW}$ & $0.18 \mu \mathrm{m}$ \\
\hline$[15]$ & $\begin{array}{l}1.8-6.5 \\
\text { VAC }\end{array}$ & N/A & $95.6 \%$ & N/A & $254 \mu \mathrm{W}$ & $0.35 \mu \mathrm{m}$ \\
\hline$[16]$ & $\begin{array}{l}5-60 \\
\text { VAC }\end{array}$ & $2-5 \mathrm{~V}$ & $<99.9 \%$ & $\begin{array}{l}25 \mu \mathrm{W} \\
-1.6 \mathrm{~mW}\end{array}$ & N/A & $\begin{array}{l}0.25 \mu \mathrm{m} \\
+ \text { discrete }\end{array}$ \\
\hline$[17]$ & $\begin{array}{l}1.5-5 \\
\text { VDC }\end{array}$ & $0-4 \mathrm{~V}$ & $99 \%$ & $800 \mu \mathrm{W}$ & N/A & $0.35 \mu \mathrm{m}$ \\
\hline $\begin{array}{l}\text { This } \\
\text { Work }\end{array}$ & $\begin{array}{l}0.5-50 \\
\text { VAC/DC }\end{array}$ & $1-50 \mathrm{~V}$ & $>99 \%$ & $\begin{array}{l}10 \mu \mathrm{W}- \\
200 \mathrm{~mW}\end{array}$ & $\begin{array}{l}1 \mu \mathrm{W} \\
-60 \mathrm{~mW}\end{array}$ & $0.35 \mu \mathrm{m}$ \\
\hline
\end{tabular}

efficiency. These changes will make the circuit more efficient especially in the milliwatt power operating range. Table I compares the measured performance of the converter designed within the proposed architecture with that of state-of-the-art (SOA) of AC-DC converters designed for energy harvesters. The measured peak efficiency is similar to that obtained by other converter designs, but the featured input voltage and power range of the proposed converter is wider and so it can be used with a wider range of energy harvesters. The circuit presented in [10] has a wide input voltage range of up to $\pm 40 \mathrm{~V}$, but this converter is not integrated since its transistors and passive components are all externally connected.

The MPPT operation of the power conditioning integrated circuit was shown to be capable of maintaining the output voltage within $99 \%$ of maximum power point in all the tests carried out. Table II compares the performance of the proposed circuit with that of other designs reported in literature. This circuit has the widest input and output voltage and power range and works with both AC and DC input voltages. Nonetheless, the efficiency levels are very similar to that of the other works, while using either a similar or even cheaper fabrication technology.

Once the fabrication of the voltage regulating DC-DC converter is carried out, it will be connected to the output of the AC/DC-to-DC converter with MPPT control, in order to generate a constant output voltage. The performance of the complete circuit will be tested and evaluated with various types of energy harvesters.

\section{ACKNOWLEDGEMENTS}

The research work disclosed in this publication is funded by the ENDEAVOUR Scholarship Scheme (Malta). The scholarship may be part-financed by the European Union - European Social Fund (ESF) under Operational Program II - Cohesion Policy 2014-2020, "Investing in human capital to create more opportunities and promote the wellbeing of society". 


\section{REFERENCES}

[1] F. Yildiz, "Potential Ambient Energy-Harvesting Sources and Techniques," Journal of Technology Studies, vol. 35, no. 1, pp. 40-48, 2009.

[2] John Donovan, Mouser Electronics, "New Applications for Energy Harvesting," Website: https://eu.mouser.com/applications/energyharvesting-new-applications/ Accessible: 27-Mar-2019, 2018.

[3] S. R. Ijjada, R. Sirigiri, B. Kumar, and V. M. Rao, "Design of high efficient \& low power basic gates in subthreshold region," International Journal of Advances in Engineering \& Technology, vol. 1, no. 2, p. 215, 2011.

[4] F. Galea, O. Casha, I. Grech, E. Gatt, and J. Micallef, "A CMOS MPPT power conditioning circuit for energy harvesters," in 2017 24th IEEE International Conference on Electronics, Circuits and Systems (ICECS). IEEE, 2017, pp. 442-445.

[5] G. D. Szarka, S. G. Burrow, and B. H. Stark, "Ultralow power, fully autonomous boost rectifier for electromagnetic energy harvesters," IEEE Transactions on Power Electronics, vol. 28, no. 7, pp. 3353-3362, 2013.

[6] T. Ozaki, T. Hirose, T. Nagai, K. Tsubaki, N. Kuroki, and M. Numa, "A 0.21-V Minimum Input, 73.6\% Maximum Efficiency, Fully Integrated Voltage Boost Converter with MPPT for Low-voltage Energy Harvesters," in European Solid State Circuits Conference (ESSCIRC), ESSCIRC 2014-40th. IEEE, 2014, pp. 255-258.

[7] X. Liu and E. Sanchez-Sinencio, "A 0.45-to-3V Reconfigurable Chargepump Energy Harvester with Two-dimensional MPPT for Internet of Things," in Solid-State Circuits Conference-(ISSCC), 2015 IEEE International. IEEE, 2015, pp. 1-3.

[8] F. Galea, O. Casha, I. Grech, E. Gatt, and J. Micallef, "Ultra Low Frequency Low Power CMOS Oscillators for MPPT and Switch Mode Power Supplies," in 2018 14th Conference on Ph. D. Research in Microelectronics and Electronics (PRIME). IEEE, 2018, pp. 121-124.

[9] — " "An Ultra Low Power CMOS MPPT Power Conditioning Circuit for Energy Harvesters," in 2020 Conference on IEEE International Symposium on Circuits and Systems (ISCAS). IEEE, 2020.

[10] P. Gasnier, J. Willemin, S. Boisseau, G. Despesse, C. Condemine, G. Gouvernet, and J.-J. Chaillout, "An autonomous piezoelectric energy harvesting IC based on a synchronous multi-shot technique," IEEE Journal of Solid-State Circuits, vol. 49, no. 7, pp. 1561-1570, 2014.

[11] D. Kwon and G. A. Rincon-Mora, "A single-inductor AC-DC piezoelectric energy-harvester/battery-charger IC converting $\pm(0.35$ to $1.2 \mathrm{~V})$ to $(2.7$ to $4.5 \mathrm{~V}), "$ in 2010 IEEE International Solid-State Circuits Conference-(ISSCC). IEEE, 2010, pp. 494-495.

[12] C.-H. Chen, H.-C. Chen, Y.-S. Huang, P.-H. Hsieh, P.-H. Wu, and Y.C. Shu, "A series-SSHI-PHI interface circuit for piezoelectric energy harvesting with $163 \%$ improvement in extracted power at off-resonance," in 2016 IEEE Asian Solid-State Circuits Conference (A-SSCC). IEEE, 2016, pp. 29-32.

[13] H. Uluşan, K. Gharehbaghi, Ö. Zorlu, A. Muhtaroğlu, and H. Külah, "A fully integrated and battery-free interface for low-voltage electromagnetic energy harvesters," IEEE Transactions on Power Electronics, vol. 30, no. 7, pp. 3712-3719, 2014.

[14] Y. Rao and D. P. Arnold, "An input-powered vibrational energy harvesting interface circuit with zero standby power," IEEE Transactions on Power Electronics, vol. 26, no. 12, pp. 3524-3533, 2011.

[15] C. Lu, C.-Y. Tsui, and W.-H. Ki, "Vibration energy scavenging system with maximum power tracking for micropower applications," IEEE transactions on very large scale integration (VLSI) systems, vol. 19, no. 11, pp. 2109-2119, 2010.

[16] S. Stanzione, C. van Liempd, R. van Schaijk, Y. Naito, R. F. Yazicioglu, and C. Van Hoof, "A self-biased 5-to-60V input voltage and 25-to$1600 \mu \mathrm{W}$ integrated DC-DC buck converter with fully analog MPPT algorithm reaching up to $88 \%$ end-to-end efficiency," in 2013 IEEE International Solid-State Circuits Conference Digest of Technical Papers. IEEE, 2013, pp. 74-75.

[17] H. Kim, S. Kim, C.-K. Kwon, Y.-J. Min, C. Kim, and S.-W. Kim, "An energy-efficient fast maximum power point tracking circuit in an $800-\mu \mathrm{W}$ photovoltaic energy harvester," IEEE transactions on power electronics, vol. 28, no. 6, pp. 2927-2935, 2012.

\section{Creative Commons Attribution License 4.0 (Attribution 4.0 International, CC BY 4.0)}

This article is published under the terms of the Creative Commons Attribution License 4.0

https://creativecommons.org/licenses/by/4.0/deed.en_US 